\title{
Параметры пленок ZnO с дырочным типом проводимости, полученных методом высокочастотного магнетронного распыления
}

\author{
(C) М.М. Мездрогина ${ }^{1}$, А.Я. Виноградов ${ }^{1}$, В.С. Левицкий ${ }^{2}$, Е.Е. Терукова ${ }^{2}$, \\ Ю.В. Кожанова ${ }^{3}$, А.С. Агликов ${ }^{2}$ \\ ${ }^{1}$ Физико-технический институт им. А.Ф. Иоффре Российской академии наук, \\ 194021 Санкт-Петербург, Россия \\ ${ }^{2}$ Санкт-Петербургский государственный электротехнический университет \\ „ЛЭТИ“ им. В.И. Ульянова (Ленина), \\ 197376 Санкт-Петербург, Россия \\ ${ }^{3}$ Санкт-Петербургский государственный политехнический университет Петра Великого, \\ 195251 Санкт-Петербург, Россия \\ E-mail: Margaret.m@mail.ioffe.ru
}

(Получена 25 октября 2016 г. Принята к печати 3 ноября 2016 г.)

\begin{abstract}
Уменьшение концентрации дефектов в пленках $\mathrm{ZnO}$, полученных методом высокочастотного магнетронного распыления, дает возможность эффективного легирования акцепторными примесями как в катионной $(\mathrm{Li})$, так и анионной подрешетках $\left(\mathrm{N}^{+}\right)$и получение дырочного типа проводимости с воспроизводимыми параметрами (концентрации, подвижности) носителей заряда. Легирование азотом производилось с помощью отжига пленок $\mathrm{ZnO}$ в атмосфере высокочастотного газового разряда. В результате измерений с помощью эффекта Холла (методика Ван-дер-Пау) показано, что использование тонких слоев Eu, нанесенных на поверхность $\mathrm{ZnO}$-пленок, приводит к увеличению концентрации и подвижности основных носителей заряда. Введение металлических примесей, отличающихся по размерам ионных радиусов ( $\mathrm{Ag}, \mathrm{Au})$, в катионную подрешетку пленок $\mathrm{ZnO}$ с целью компенсации напряжений несоответствия дает возможность увеличения концентрации центров излучательной рекомбинации.
\end{abstract}

DOI: 10.21883/FTP.2017.05.44411.8437

\section{1. Введение}

В настоящее время исследованиям пленок $\mathrm{ZnO}$ прямозонного широкозонного полупроводника, перспективного материала для создания различных приборов на его основе, посвящен целый ряд работ [1-6].

Основное внимание в публикациях уделяется решению не полностью реализованной в настоящее время проблемы: получения воспроизводимых и стабильных результатов измерений в пленках $\mathrm{ZnO}$ с дырочным типом проводимости.

Высокочастотное магнетронное распыление является одним из широко используемых методов, позволяющих наносить пленки $\mathrm{ZnO}$ на подложки с достаточно высокой скоростью роста при относительно малой интенсивности бомбардировки поверхности и простом конструктивном исполнении, небольших энергетических затратах.

В качестве объектов исследований были выбраны пленки $\mathrm{ZnO}$, рост которых происходит в случае использования высокочастотного магнетронного распыления по механизму пар-кристалл и реализации процессов самоорганизации [4].

Легирование пленок $\mathrm{ZnO}$ металлическими примесями - $\mathrm{Li}, \mathrm{Ag}, \mathrm{Au}$ в катионной подрешетке производилось методом диффузии [7] газовой примесью - азотом $\left(\mathrm{N}^{+}\right)$, в анионной подрешетке производилось в процессе отжига в высокочастотном газовом разряде смеси азота и аргона.
Введение азота в анионную подрешетку дает возможность получения пленок $\mathrm{ZnO}$ с дырочным типом проводимости. Азот как примесь замещения, занимая место точечных вакансий $V_{\mathrm{O}}$, уменьшая их концентрацию, может быть акцепторной примесью в $\mathrm{ZnO}$, поскольку величина электроотрицательности у азота $(3,0)$ меньше, чем у кислорода $(3,5)$, ионный радиус $\mathrm{N}^{+}$почти равен ионному радиусу $\mathrm{O}^{+}[8,9]$.

Наиболее существенным вопросом является определение оптимальной электрически активной концентрации примеси, поскольку общая концентрация азота может быть значительно больше, что способствует увеличению концентрации дефектов в полупроводниковой матрице $\mathrm{ZnO}$.

Эффективность легирования металлическими примесями в катионной подрешетке пленок $\mathrm{ZnO}$ (при прочих равных условиях) при замещении металлом дефекта $V_{\mathrm{Zn}}$ (вакансия $\mathrm{Zn}$ ) зависит от размеров ионного радиуса легирующего металла.

Для структуры $\mathrm{ZnO}$ в качестве примеси замещения точечных дефектов $V_{\mathrm{Zn}}$ может быть использован $\mathrm{Li}$, так как величина ионного радиуса $\mathrm{Li}$ близка к величине ионного радиуса $\mathrm{Zn}$.

Для кристаллов $\mathrm{ZnO}$ водород является одной из основных примесей, образующих дефекты донорного типа. Для пленок, полученных методом магнетронного распыления при температуре подложки $(500<T<700)^{\circ} \mathrm{C}$, наличие примеси водорода в процессе осаждения мало 
вероятно, но имеется вероятность адсорбции ОН-комплексов из воздуха на поверхности пленки, имеющей развитый рельеф по данным топографии поверхности, полученной методом атомно-силовой микроскопии (АСM) [4].

Легирование наночастицами $\mathrm{Ag}$, $\mathrm{Au}$ пленок $\mathrm{ZnO}$ интенсивно исследуется в связи с реализацией воздействия наночастиц данных металлов на параметры формирования межзеренных границ, с возможностью наблюдения линейных и нелинейных оптических эффектов, в частности, с реализацией поверхностного плазмонного резонанса, который зависит от размеров наночастиц, что может приводить к увеличению интенсивности излучения [7,10,11,12].

Кроме того, легирование $\mathrm{Ag}$, величина ионного радиуса которого равна 0.113 нм, т. е. больше размеров ионных радиусов компонентов соединения $\mathrm{ZnO}$, может привести к компенсации напряжений сжатия в пленке, вызванных наличием напряжений несоответствия из-за разницы параметров кристаллической решетки подложки (сапфира) и осажденной пленки, что может привести к увеличению концентрации центров излучательной рекомбинации.

Цель данной работы заключается в оценке эффективности влияния легирования газовой примесью $\left(\mathrm{N}^{+}\right)$в анионной подрешетке или металлическими примесями $(\mathrm{Li}, \mathrm{Ag}, \mathrm{Au})$ в катионной подрешетке на электрофизические параметры (тип проводимости, концентрацию, подвижность носителей заряда), вид спектров близкраевой фотолюминесценции (БКФЛ), пленок $\mathrm{ZnO}$, полученных высокочастотным магнетронным распылением.

\section{2. Эксперимент}

Измерения параметров исследуемых пленок $\mathrm{ZnO}$ (концентрации, типа проводимости, подвижности носителей заряда) производились на установке для измерений эффекта Холла (методика Ван-дер-Пау), оценка изменения концентрации центров безызлучательной рекомбинации проводилась на основе анализа спектров фотолюминесценции.

Для измерения спектров фотолюминесценции использовались следующие типы лазеров:

1) $\mathrm{Ar}^{+}$-лазер с удвоением частоты $(\lambda=244 \mathrm{HM}$, мощность в импульсе при расфокусированном пучке $\left.10 \kappa \mathrm{BT} / \mathrm{cm}^{2}\right)$;

2) $\mathrm{Nd}$ :YAG-лазер $(\lambda=532 \mathrm{HM}, \quad$ диаметр пятна 5 мкм, мощность 1 мВт, плотность возбуждения $W=$ $=4.74 \cdot 10^{23}$ фотон $\left./ \mathrm{c} \cdot \mathrm{cm}^{2}\right)$ при измерении спектров излучения кристаллических пленок $\mathrm{ZnO}$, легированных $\mathrm{Eu}$.

Для корректного сравнения спектров излучения различных пленок $\mathrm{ZnO}$ контролируемые параметры (угол падения луча, интенсивность возбуждающего света, температура измерения) были постоянными. Температура измерений была $T=77$ и $300 \mathrm{~K}$.

По данным рентгеноструктурного анализа (установка УРС-59), исследуемые пленки $\mathrm{ZnO}$ являются кристал- лическими, ось $z$ (1111) перпендикулярна плоскости пленок.

Зарядовое состояние кодопанта $\mathrm{Eu}$ в исследованных в данной работе $\mathrm{ZnO}$-пленках 2+, малая часть примеси имела зарядовое состояние $3+$ [6].

Примесь азота в исследуемые пленки вводилась из высокочастотного разряда смеси аргона с азотом, при варьировании времени и мощности разряда. Концентрация атомарного азота ранее была измерена методом спектрометрии ядерных реакций с дейтронами на аналитическом комплексе ПИЯФ РАН, созданном на электростатическом ускорителе ЭСУ-2 [13].

Объемные кристаллы $\mathrm{ZnO}(c-\mathrm{ZnO})$, используемые в данной работе в качестве подложек, были получены двумя различными методами: гидротермальным и газофазным. В кристаллах $c$ - ZnO, полученных гидротермальным методом, как правило, имеются фоновые примеси $\mathrm{Fe}$ и $\mathrm{Cu}$, наличие которых определялось методом рентгеновской флуоресценции. Концентрация $\mathrm{Fe}\left(C_{\mathrm{Fe}}\right)$ оценивалась по интенсивности излучения линии $K_{\alpha}$. Для подложек c-ZnO, в используемых в данной работе, концентрация $\mathrm{Fe}$ составляла $10^{17}<C_{\mathrm{Fe}}<10^{18} \mathrm{~cm}^{-3}$, a концентрация $\mathrm{Cu}$ была на порядок меньше [5].

Вследствие большой концентрации дефектов донорного типа в пленках $\mathrm{ZnO}$ влияние мелких акцепторных примесей, введение которых могло бы способствовать реализации устойчивого дырочного типа проводимости, приводит лишь к увеличению общей концентрации дефектов.

Фоновая акцепторная примесь в кристаллах $\mathrm{ZnO}-\mathrm{Cu}^{2+}$ приводит к появлению глубокого акцепторного уровня [5].

Таким образом, нанесение пленок $\mathrm{ZnO}$ методом высокочастотного магнетронного распыления с воспроизводимым дырочным типом проводимости может быть реализовано лишь при уменьшении общей концентрации дефектов донорного типа в исходной полупроводниковой матрице.

\section{3. Экспериментальные результаты}

Основными дефектами пленок $\mathrm{ZnO}$, полученных методом высокочастотного магнетронного распыления, являются протяженные дефекты, появление которых связано с различием постоянных решеток подложки и пленки, т.е. с наличием напряжений несоответствия, прорастанием протяженных дефектов и с диффузией примесей из подложки. Точечные дефекты вакансии $\mathrm{Zn} V_{\mathrm{Zn}}$ (дефект акцепторного типа) и $\mathrm{O} V_{\mathrm{O}}$ (дефект донорного типа) обусловлены не сохранением стехиометрического состава, неоднородностью состава вследствие процессов временно́й или пространственной самоорганизации на поверхности пленки [4].

Проблема уменьшения концентрации дефектов решается путем оптимизации процессов нанесения пленок: температуры и материала подложек, высокочастотной 
мощности, скорости роста. Оптимизация технологических параметров осаждения приводит к уменьшению центров безызлучательной рекомбинации.

На рис. 1, $a$ представлены спектры БКФЛ ZnO-пленок, нанесенных при малой скорости осаждения $(0.1-0.2 \mathrm{Hm} / \mathrm{c})$.

Увеличение скорости осаждения при одинаковых температуре и материале подложки (рис. 2, кривая 3) приводит к уменьшению интенсивности излучения на порядок и к сдвигу максимума излучения $\left(\lambda_{\max }\right)$ в длинноволновую область спектра $\left(\lambda_{\max }=369.5\right.$ нм при малой скорости осаждения и $\lambda_{\max }=379.5$ нм при увеличении скорости осаждения), что совпадает с литературными данными $[9,12]$.

На рис. 2 представлена зависимость вида спектров ФЛ в УФ-области пленок $\mathrm{ZnO}$, нанесенных с большой скоростью $(1-1.2 \mathrm{Hм} / \mathrm{c})$, при варьировании материала подложки и температуры $520<T<670^{\circ} \mathrm{C}$ (кривые $1-3$ на рис. 2). Использование подложек из монокристаллического $c$ - $\mathrm{ZnO}$, полученного методом газофазного роста, при увеличении температуры роста $\mathrm{ZnO}$ пленок приводит к уменьшению концентрации дефектов, к уве-
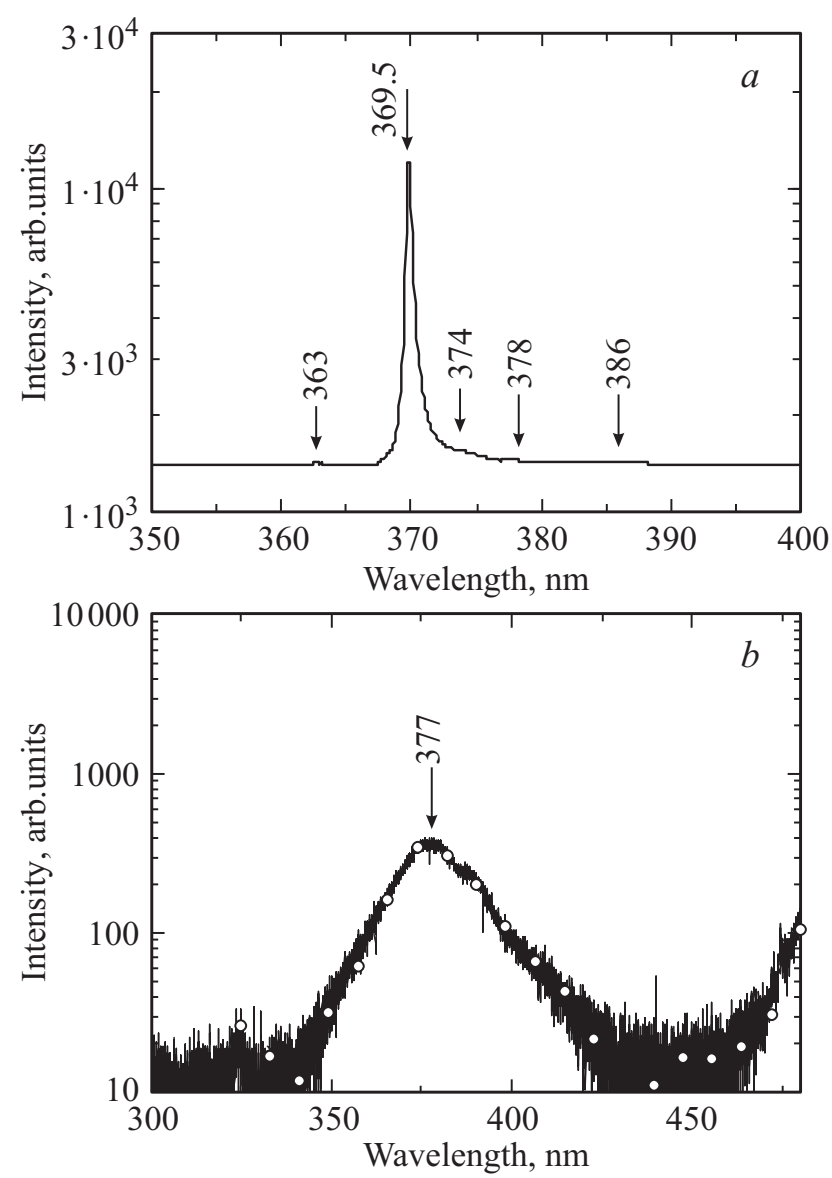

Рис. 1. $a-$ спектр БКФЛ пленок $\mathrm{ZnO}$, нанесенных при малой скорости осаждения $(0.1-0.2) \mathrm{Hм} / \mathrm{c} ; b-$ спектр БКФЛ пленок $\mathrm{ZnO}$, нанесенных при большой скорости осаждения $(1-1.2) \mathrm{HM} / \mathrm{c}$.

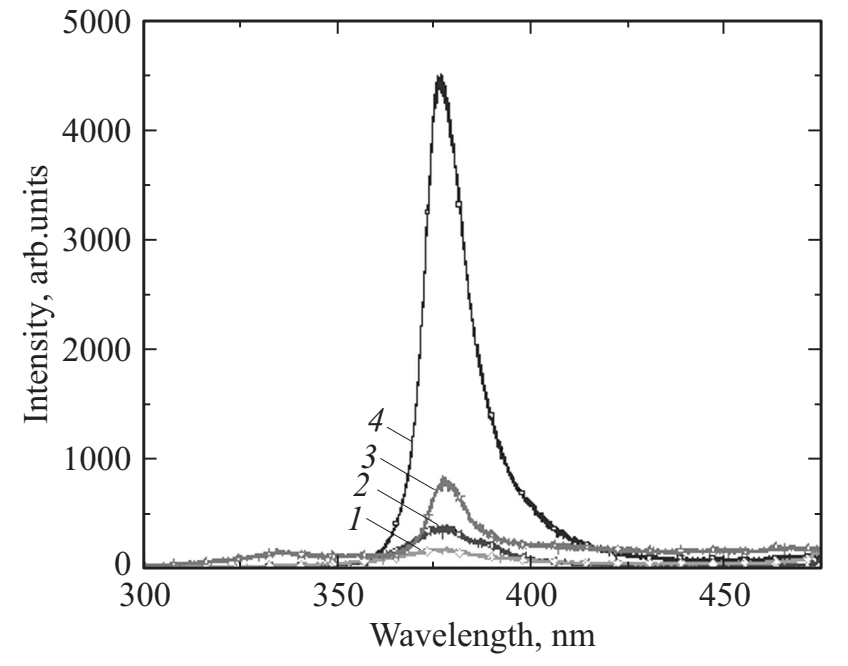

Рис. 2. Влияние температуры и материала подложки на вид спектров БКФЛ пленок $\mathrm{ZnO}$, нанесенных со скоростью $(1-1.2) \mathrm{Hм} / \mathrm{c}: 1,2,3-$ сапфир, $4-c-\mathrm{ZnO}$, полученный газофазным методом $\left(1-520^{\circ} \mathrm{C}, 2-650^{\circ} \mathrm{C}, 3-667^{\circ} \mathrm{C}\right.$, $\left.4-667^{\circ} \mathrm{C}\right)$.

личению концентрации центров излучательной рекомбинации на порядок по сравнению с интенсивностью излучения пленок, нанесенных на сапфир (кривые 3 и 4 на рис. 2).

На установке по исследованию эффекта Холла (методика Ван-дер-Пау) были измерены параметры (подвижность, тип и концентрация носителей) пленок, осажденных на подложках из монокристаллического $c-\mathrm{ZnO}$, полученного методом газофазного роста (рис. 2, кривая 4), с дополнительно нанесенным тонким слоем $(10<d<20$ нм $) \mathrm{Eu}$. Показано, что пленки имеют электронный тип проводимости: концентрация носителей $n=10^{21} \mathrm{~cm}^{-3}$, а подвижность $\mu=145-147 \mathrm{~cm}^{2} /$ В $\cdot$ с. По данным исследований, выполненных по определению тех же параметров в пленках $n-\mathrm{ZnO}$, имеет место такая же концентрация носителей, но величина подвижности $34.8 \mathrm{~cm}^{2} /$ В · с. [11], т. е. легирование Еu можно рассматривать как процесс геттерирования дефектов полупроводниковой матрицы [6].

На рис. 3 представлены изменения вида спектров ФЛ пленок $\mathrm{ZnO}$, нанесенных при постоянной температуре, варьировании мощности и материала подложки: пластины плавленого кварца, монокристаллы $c-\mathrm{ZnO}$, полученные газофазным и гидротермальным методами, монокристаллический кремний с дырочным типом проводимости марки КДБ-4 [111].

Одним из методов уменьшения напряжений несоответствия при росте пленок $\mathrm{ZnO}$ является использование подложек из пластин плавленого кварца (далее - кварца). В спектрах ФЛ (рис. 3) пленок $\mathrm{ZnO}$, выращенных на подложках из кварца, интенсивность излучения $I$ равна интенсивности излучения $I$ пленок, выращенных на подложках $c$ - $\mathrm{ZnO}$, полученных методом газофазного 


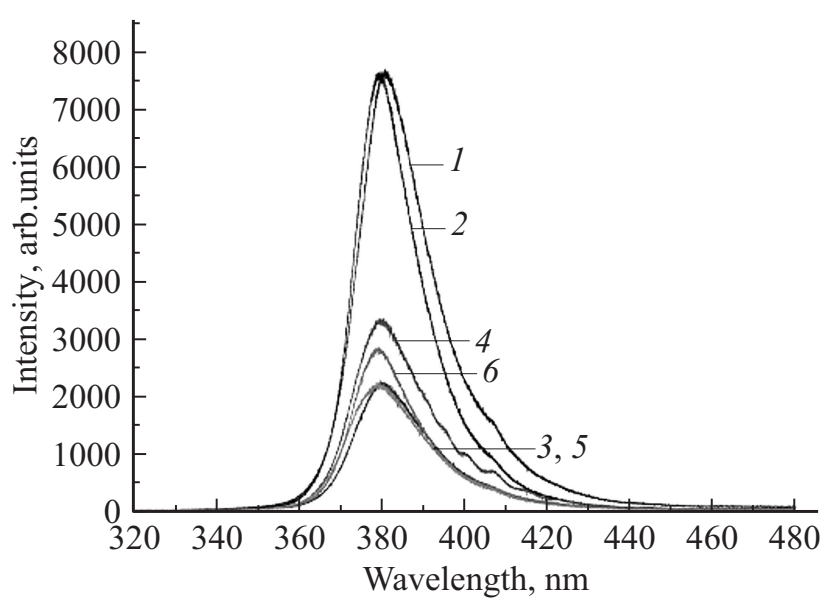

Рис. 3. Вид спектров БКФЛ пленок $\mathrm{ZnO}$, нанесенных при постоянной температуре, варьировании мощности, материала подложки: 1 - пластины плавленого кварца $\left(30 \mathrm{~B}\right.$, $\left.630^{\circ} \mathrm{C}\right)$; 2 - монокристаллы $c-\mathrm{ZnO}$, полученные газофазным методом при малой мощности $\left(7.2 \mathrm{~B}, 630^{\circ} \mathrm{C}\right) ; 3$ - монокристаллы $c$ - $\mathrm{ZnO}$, полученные гидротермальным методом при малой мощности $\left(7.2 \mathrm{BT}, 630^{\circ} \mathrm{C}\right) ; 4$ - монокристаллический кремний с дырочным типом проводимости марки КДБ-4 [111] (30Вт, $\left.630^{\circ} \mathrm{C}\right) ; 5$ - монокристаллический кремний с дырочным типом проводимости марки КДБ-4 [111] при малой мощности $\left(7.2 \mathrm{~B}, 630^{\circ} \mathrm{C}\right) ; 6$ - пластины плавленого кварца при увеличении мощности $\left(30 \mathrm{~B}, 630^{\circ} \mathrm{C}\right)$.

роста, величина полной ширины на половине высоты $F W H M=19$ мэВ, $\lambda_{\max }=380$ нм (кривые 1,2 на рис. 3 ).

Использование подложек КДБ-4 и сапфира $\left(T=630^{\circ} \mathrm{C}\right.$, скорость нанесения постоянна) приводит к уменьшению $I$ в 1.5 раза по сравнению с $I$ пленок, выращенных на подложках из $c-\mathrm{ZnO}$, полученных газофазным методом, но величины $F W H M=15.6-15.4$ мэВ и $\lambda_{\max }=379-378$ нм практически не меняются (кривые 3, 6 на рис. 3).

При одной и той же скорости роста пленок (высокочастотной мощности) использование подложек $c-\mathrm{ZnO}$, полученных методом газофазного роста, приводит к 4-кратному увеличению $I$ по сравнению с $I$ пленок, выращенных на подложках $c$ - $\mathrm{ZnO}$, полученных методом гидротермального роста. Для пленок, выращенных на кристаллах $c$ - $\mathrm{ZnO}$, полученных методом газофазного роста (пленки I типа): $F W H M=19$ мэВ, $\lambda_{\max }=377$ нм. Для пленок, выращенных на $c-\mathrm{ZnO}$ (пленки II типа), полученных гидротермальным методом: $F W H M=15.3$ мэВ, $\lambda_{\max }=382$ нм (кривые 2 и 4 на рис. 3).

Пленки I и II типов после измерений спектров ФЛ были отожжены в газовой смеси в атмосфере высокочастотного разряда при варьировании времени и мощности разряда. Параметры пленок I типа, измеренных по методике Ван-дер-Пау, были следующими:

1) концентрация неосновных носителей $5.9 \cdot 10^{21} \mathrm{~cm}^{-3}$;

2) подвижность $-330 \mathrm{~B} / \mathrm{cm}^{-2} \cdot \mathrm{c}$;
3) удельное сопротивление $-3.34 \cdot 10^{-6} \mathrm{OM} \cdot \mathrm{cm}$.

Параметры пленок II типа, осажденных на $c-\mathrm{ZnO}$ и отожженных в тех же условиях, были следующими:

1) концентрация неосновных носителей $4.5 \cdot 10^{20} \mathrm{~cm}^{-3}$

2) подвижность $-29.2 \mathrm{~B} / \mathrm{cm}^{-2} \cdot \mathrm{c}$,

$3)$ удельное сопротивление $-5.04 \cdot 10^{-4}$ Ом $\cdot$ см.

В спектрах ФЛ пленок I и II типа (до отжига в азотной плазме) наблюдается сдвиг $\lambda_{\max }$ в длинноволновую область спектра (ср. $\lambda_{\max }=377$ и 382 нм). Наличие фоновых примесей $\mathrm{Fe}, \mathrm{Cu}$ в подложках $c-\mathrm{ZnO}$ (пленки II типа) приводит к уменьшению концентрации неосновных носителей заряда и подвижности, т. е. концентрация дефектов подложки определяет параметры нанесенного, а затем отожженного слоя даже при отсутствии напряжений несоответствия [14].
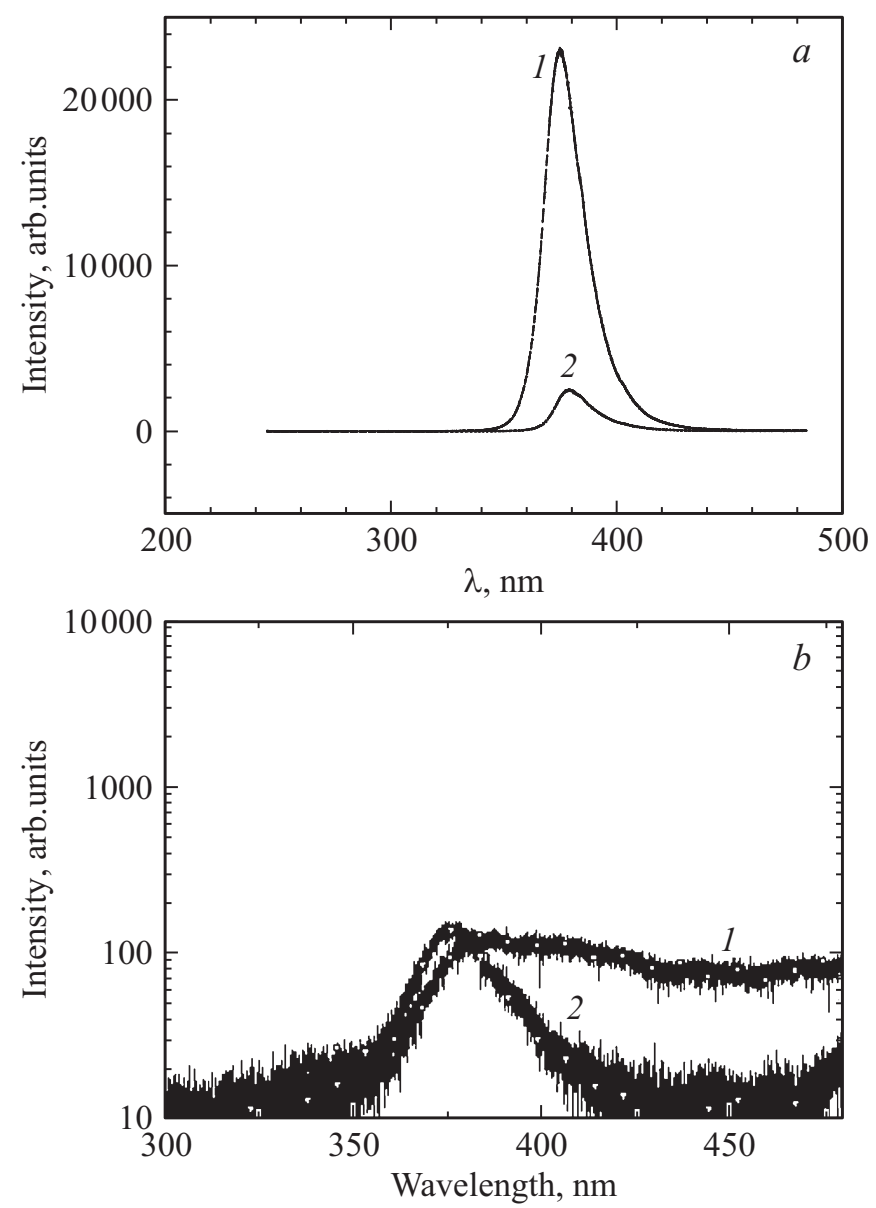

Рис. 4. $a-$ спектры БКФЛ пленок $\mathrm{ZnO}$ с дырочным типом проводимости (отжиг в атомарном азоте, легирование $\mathrm{Li}$ ) при малой высокочастотной мощности разряда: 1 - спектр БКФЛ пленки $\mathrm{ZnO}$ после отжига в атомарном азоте; 2 спектр БКФЛ пленки $\mathrm{ZnO}$, легированной $\mathrm{Li}$ и отожженной в атомарном азоте. $b-$ спектры БКФЛ пленок $\mathrm{ZnO}$ с дырочным типом проводимости (отжиг в атомарном азоте) при увеличении высокочастотной мощности: 1 - спектр БКФЛ пленки, легированной $\mathrm{Li}$ и отожженной в атомарном азоте; 2 - спектр БКФЛ пленки после отжига в атомарном азоте. 


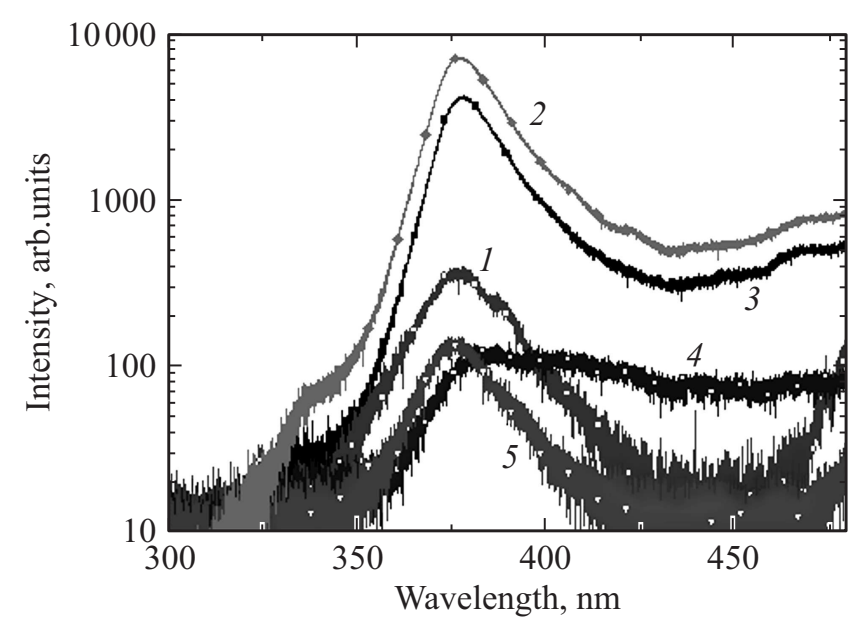

Рис. 5. Спектры БКФЛ пленок $\mathrm{ZnO}$, осажденных при $T=650^{\circ} \mathrm{C}$ на сапфире, легированных $\mathrm{Li}$, легированных $\mathrm{N}^{+}$: 1 - спектр ФЛ нелегированных пленок $\mathrm{ZnO} ; 2$ - тех же пленок, легированных $\mathrm{Li} ; 3$ - спектр БКФЛ пленок $\mathrm{ZnO}$, легированных $\mathrm{N}^{+} ; 4-$ спектр ФЛ пленок, легированных $\mathrm{N}^{+}$ при увеличении времени отжига.

Спектры ФЛ пленок I и II типов после отжига в атмосфере высокочастотного разряда при увеличении времени отжига и высокочастотной мощности приведены на рис. 4, $a$.

Спектры БКФЛ пленок $\mathrm{ZnO}$ после отжига в атмосфере высокочастотного разряда (при малом значении высокочастотной мощности) газовой смеси аргона и азота, после отжига и последовательного легирования Li представлены на рис. $4, b$.

Введение газовой примеси азота в анионную подрешетку, как и введение Li в катионную подрешетку, приводит к увеличению количества центров излучательной рекомбинации (рис. 5). Как видно из спектров ФЛ в УФ-области (рис. 5), интенсивность излучения пленок $\mathrm{ZnO}$, осажденных при $T=650^{\circ} \mathrm{C}$ на сапфире, легированных $\mathrm{Li}$ (кривая 2), легированных $\mathrm{N}^{+}$(кривая 3), увеличивается более чем на порядок по сравнению с интенсивностью излучения нелегированной пленки (кривая 1 на рис. 5).

При одновременном легировании Li, N (рис. 5, кривая 5) спектр ФЛ однородно уширен, интенсивность излучения существенно уменьшается по сравнению с интенсивностью излучения при легировании одной примесью $\left(\mathrm{Li}, \mathrm{N}^{+}\right)$и по сравнению с интенсивностью излучения нелегированных пленок (кривые $1-3$ на рис. 5).

Параметры отожженных в атомарном азоте при увеличении времени отжига (рис. 5, кривая 4) пленок $\mathrm{ZnO}$ (удельная концентрация, тип проводимости, подвижность носителей заряда), измеренные по методике Ван-дер-Пау, были следующими:

1) концентрация неосновных носителей $2.71 \cdot 10^{18} \mathrm{~cm}^{-3}$;

2) подвижность $-3.1 \mathrm{~B} / \mathrm{cm}^{-2} \cdot \mathrm{c}$;

3) удельное сопротивление $-4.68 \cdot 10^{-1} \mathrm{OM} \cdot \mathrm{cm}$.
Параметры пленок, легированных Li, а затем отожженных в азоте с теми же параметрами, что и в предыдущем случае, т.е. при тех же значениях времени, температуры, мощности разряда:

1) концентрация неосновных носителей заряда $1.7 \cdot 10^{17} \mathrm{~cm}^{-3}$

2) подвижность $-3.81 \mathrm{~B} / \mathrm{cm}^{-2} \cdot \mathrm{c}$;

$3)$ удельное сопротивление -2.66 Ом · см.

Результаты измерений по методике Ван-дер-Пау легированных двумя примесями $\left(\mathrm{N}^{+}\right.$и $\left.\mathrm{Li}\right)$ пленок $\mathrm{ZnO}$ коррелируют с результатами измерений спектров ФЛ, т.е. введение второй примеси уменьшает концентрацию центров излучательной рекомбинации, уменьшает концентрацию электрически активной доли примеси вследствие увеличения общей концентрации дефектов.

По всей вероятности, для $\mathrm{ZnO}$ легирование $\mathrm{Li}$, как для $\mathrm{GaN}$ легирование $\mathrm{Mg}$, смогло бы привести к получению дырочного типа проводимости, но при существенном уменьшении концентрации дефектов в исходной полупроводниковой матрице.

Эффективность легирования атомарным азотом, т.е. увеличение концентрации электрически активной части примеси, по всей вероятности, обусловлена большим коэффициентом диффузии азота в матрице $\mathrm{ZnO}$, поскольку ионы азота имеют большую энергию $(10<E<5)$ эВ газового разряда. Металлическая примесь $\mathrm{Li}$ при использовании метода диффузии вводится в нейтральном состоянии.

Введение металлических примесей, отличающихся по размерам ионных радиусов (например, $\mathrm{Ag}-0.113 \mathrm{нм}$ ), в катионную подрешетку пленок $\mathrm{ZnO}$ с целью компенсации напряжений несоответствия, по всей вероятности, вызывающих появление напряжений сжатия в процессе роста пленки, дает возможность увеличения концентрации центров излучательной рекомбинации [15].

\section{4. Заключение}

В результате измерений спектров БКФЛ показано, что уменьшение напряжений несоответствия - использование подложек из кварца, монокристаллического $c-\mathrm{ZnO}$, полученного газофазным методом - при оптимальной величине скорости осаждения приводит к уменьшению концентрации дефектов, увеличению концентрации центров излучательной рекомбинации пленок $\mathrm{ZnO}$, полученных методом магнетронного распыления на переменном токе.

Использование тонких слоев $\mathrm{Eu}$, нанесенных на поверхность $\mathrm{ZnO}$ пленок, приводит к увеличению концентрации и подвижности основных носителей заряда.

Уменьшение концентрации дефектов в пленках $\mathrm{ZnO}$ дает возможность эффективного легирования акцепторными примесями как в катионной, так и анионной подрешетках и получения дырочного типа проводимости с воспроизводимыми параметрами (концентрации, подвижности) неосновных носителей заряда. 


\section{Список литературы}

[1] P.M. Parthangal, R.E. Cavicchi, M.R. Zachariah. Nanotechnology, 2006. 17. 3786 (2006).

[2] H.J. Lozukowski, W.M. Jadwisienczak. Phys. Status Solidi B, 1 (2007).

[3] М.М. Мездрогина, М.В. Еременко, А.Н. Смирнов, В.Н. Петров, Е.И. Теруков. ФТП, 49 (8), 1016 (2015).

[4] М.М. Мездрогина, М.В. Еременко, В.С. Левицкий, В.Н. Петров, Е.И. Теруков, Н.М. Лянгузов, Е.М. Кайдашев. ФТП, 49 (11), 1521 (2015).

[5] М.М. Мездрогина, Э.Ю. Даниловский, Р.В. Кузьмин, Н.К. Полетаев, И.Н. Трапезникова, М.В. Чукичев, Г.А. Бордовский, А.В. Марченко, М.В. Еременко. ФТП, 44 (4), 445 (2010).

[6] М.М. Мездрогина, Ю.В. Кожанова, М.В. Еременко, Е.И. Теруков. ФТП, 46 (7), 925 (2012).

[7] М.М. Мездрогина, М.В. Еременко, С.М. Голубенко, Е.С. Москаленко. ФТТ, 54 (1), 182 (2012).

[8] Ж.П. Сюше. Физическая химия полупроводников (М., Металлургия, 1969) с. 127.

[9] W.W. Liu, B. Yao, Z.Z. Zhang, Y.F. Li, B.H. Li, C.H. Shan, J.Y. Zhang, D.Z. Chen, X.W. Fan. J. Appl. Phys., 109, 093518 (2011).

[10] Н.М. Лядов, А.И. Гумаров, В.Ф. Валеев, Н.И. Нуждин, В.В. Базаров, И.А. Файзрахманов. ЖТФ, 54 (5), 62 (2014).

[11] D.C. Look, K.D. Leedy, D.B. Thomson, B. Wang. J. Appl. Phys., 115, 0122002 (2014).

[12] C.W. Cheng, E.J. Sie, B. Liu, C.H.A. Huan, T.C. Sum, H.D. Sun, H.J. Fan. Appl. Phys. Lett., 97, 071107 (2010).

[13] В.М. Лебедев. Сб. тр. IV Междунар. конф. „Аморфные и микрокристаллические полупроводники“" (СПб., 2004).

[14] S. Chalva, M. Saroha, R.K. Kotnala. Electron. Mater. Lett., 10 (1), 73 (2014).

[15] М.М. Мездрогина, А.Я. Виноградов, М.В. Еременко, В.С.Левицкий, Е.И. Теруков, Ю.В. Кожанова. Опт. и спектр., 121 (2), 62 (2016).

Редактор А.Н. Смирнов

\section{ZnO films with $p$-type conductivity, deposited by high frequency magnetron sputtering}

M.M. Mezdrogina ${ }^{1}$, A.Ya. Vionogradov' ${ }^{1}$, V.S. Levitskii ${ }^{2}$, E.E. Terukova ${ }^{2}$, Yu.V. Kozhanova ${ }^{3}$, A.S. Aglikov ${ }^{2}$

${ }^{1}$ loffe Institute, 194021 St. Petersburg, Russia

2 St. Petersburg State Electrotechnic University, 197375 St. Petersburg, Russia

${ }^{3}$ St. Petersburg State Polytechnic

Peter Great University,

195251 St. Petersburg, Russia

Abstract It was investigated, the possibility of effective doping of $\mathrm{ZnO}$ films, deposited by high frequency magnetron sputtering, by the acceptors impurities as in cation sub lattice $(\mathrm{Li})$, as in anion sub lattice $\left(\mathrm{N}^{+}\right)$and realization $p$-type of conductivity with stable parameters (concentration, mobility of the charge currents) due to decreasing of defects concentration in the films. Annealing in the high frequency discharge in the gaseous mixture of nitrogen and argon was employed for doping of gaseous impurity. Thin films of $\mathrm{Eu}$, evaporated on the $\mathrm{ZnO}$ films, increased concentration and mobility charge currents according by Hall (techniques of Van-der-Pau) measurements. It was found the increasing the luminosity centers of recombination in $\mathrm{ZnO}$ films as conclusion by doping $\mathrm{Ag}, \mathrm{Au}$ impurities with great ionic radio in compare with ionic radio components for compensation of the tensile. 